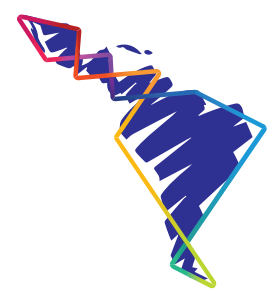

\title{
Entre el sueño de construir un hogar y las pesadillas previas a la casa propia: Nuestra ciudad y su exclusión social
}

\author{
Between the dream of building a \\ home and the nightmares previous \\ to ownership: Our city and its social \\ exclusion
}

\section{Entre o sonho de construir uma casa e os pesadelos antes de ter casa própria: A nossa cidade e a sua exclusão social}

Adriana Masís Morales

\section{Resumen}

Una de las mayores aspiraciones materiales del ser humano es la adueñarse emocional y legalmente de un espacio digno en donde habitar. Sin embargo, no solo hay un amplio entramado de dificultades a enfrentar antes de hacerse acreedor de dicho bien, sino a su vez, una gran cantidad de asuntos urbanos que afectan directamente la experiencia del habitar, a razón de que la ciudad es el contexto y vaso comunicante principal de la relación entre el ser humano y su vivienda. Las problemáticas actuales en torno a la gestión del territorio solicitan ir mucho más lejos del discurso historiográfico sobre las ciudades, el estudio del mercado inmobiliario y la creación de leyes que garantizan derechos, que en la práctica no parecen estar tan rigurosamente protegidos. Esta investigación señala los principales modos de exclusión social que enfrentamos en Costa Rica a la hora de defender el derecho a la vivienda y procurar la construcción de ciudadanía. A raíz de dicho análisis, surge la propuesta de una agenda de discusión, en donde se puntualizan los temas urgentes a tratar, para poder brindar soluciones integrales,

1 Licenciada en Arquitectura de la Universidad de Costa Rica. Arquitecta e investigadora independiente. Docente universitaria en la Universidad Creativa. Miembro colaborador del Círculo Latinoamericano de Fenomenología. Correo electrónico: adrianama59@yahoo.es. ORCID: https://orcid.org/0000-0002-4720-2609 
que realmente apelen a la convivencia y a la dinamización de la ciudad, lo cual, en conclusión, se traduce en mayor calidad de vida.

Palabras clave: Derecho a la vivienda; hogar; exclusión; urbanismo; ciudad.

\begin{abstract}
One of the greatest material aspirations of the human being is to take emotional and legal ownership of a decent space in which to live. However, not only is there a broad network of difficulties to face before becoming the creditor of said asset, but also a vast number of urban issues that directly affect the experience of home-living because the city is the context and main connection that reinforces the relationship between the human being and his home. Current problems encompassing territory management require to go much further from the historiographical discourse on cities, the study of the real estate market and the creation of laws that guarantee rights, which in practice do not seem to be so rigorously protected. The present research points out the main forms of social exclusion faced in Costa Rica when defending the right to housing and seeking to build citizenship. As a result of this analysis, a discussion agenda proposal arises, where the urgent issues to be addressed are pointed out in order to provide comprehensive solutions that really appeal to coexistence and the dynamization of the city, which, in conclusion, translates into a higher quality of life.
\end{abstract}

Keywords: Right to housing; Home; Exclusion; Urbanism; City.

\title{
Resumo
}

Uma das maiores aspirações materiais do ser humano é apropriar-se emocional e legalmente de um espaço decente para viver. Porém, não só existe uma vasta rede de dificuldades a ser enfrentada antes de se tornar credor desse bem, mas também um grande número de questões urbanas que afetam diretamente a experiência de viver, porque a cidade é o contexto e principal vaso comunicante da relação entre o ser humano e o seu lar. Os problemas atuais em torno da gestão do território exigem ir muito mais longe do discurso historiográfico sobre as cidades, do estudo do mercado imobiliário e da criação de leis que garantam direitos, que na prática não parecem ser tão rigorosamente protegidos. Esta pesquisa aponta as principais formas de exclusão social que enfrentamos na Costa Rica ao defender o direito à moradia e buscar a construção da cidadania. Como resultado desta análise surge a proposta de uma agenda de discussão, onde se especificam as questões urgentes a serem abordadas, de forma a fornecer soluções integrais que apelem realmente à convivência e à revitalização da cidade, que, em conclusão, isso se traduz em uma melhor qualidade de vida.

Palavras-chave: Direito à moradia; Casa; Exclusão; Urbanismo; Cidade. 


\section{Vivienda-casa-hogar: Una diferenciación necesaria}

De manera intuitiva, podemos reconocer que la diferencia entre los términos vivienda, casa y hogar, radica en el grado de intimidad y afectividad implícita en estos conceptos.

En el primer caso, hablar de vivienda hace referencia a una palabra de carácter técnico, que además tiene una connotación formal, jurídica y estadística; esta se encuentra, además, en el nombre de instituciones como el Banco Hipotecario de la 'Vivienda' (BANHVI), Ministerio de 'Vivienda' y Asentamientos Humanos (MIVAH), Instituto Nacional de 'Vivienda' y Urbanismo (INVU), entre otras y está estrictamente relacionada con los conceptos de residencia, domicilio y dirección.

Mientras, cuando hablamos en términos posesivos de la vivienda, hacemos un cambio y decimos "mi casa", rebasando toda aquella estructura institucional, política y legal, para acercarnos a los conceptos de hospitalidad y confianza ("siéntase en su casa"), modo de estar ("estoy como en casa") y referente respecto al resto del mundo ("hoy regreso a casa"); de manera que la casa es una estancia, conlleva el sentimiento de 'estar'; pero no deja de tratarse de un componente material.

Finalmente, cuando hablamos de "hogar", este concepto muestra el más alto grado de afectividad y alusión a lo intangible. Etimológicamente, la palabra hogar derivada del latín 'focus' (hogar), 'focaris' (de fuego) -como lugar en la casa donde se enciende la hoguera- tiene relación con la luz, el fuego, el calor, el lugar donde se preparan los alimentos, la lumbre alrededor de la que nos sentamos y, en ese sentido, se le asocia con calidez, cuido, familia y habitabilidad. Sin embargo, justamente a causa de su gran carga afectiva, el término es menos utilizado y más común en la literatura y la música; y algunas pocas veces en la sociología y el periodismo como un sinónimo de familia (como cuando se dice, "40 hogares fueron afectados por la sequía") o para referirse a las personas en condición de indigencia (cuando se les dice, "sin hogar").

En efecto, este fenómeno de utilizar el concepto de hogar en los casos en los que se carece de este bien, se evidencia en el francés (sans-abri, sin refugio), ruso (bezdomnyy, sin hogar), inglés (homeless, sin hogar), alemán (obdachlos, sin techo) y más recientemente en el español; 'sinhogarismo' (reconocida en el 2018 como neologismo válido por Fundación del Español Urgente). Esta es una manera de enfocar la problemática desde lo que verdaderamente importa, humanizando, desde un aspecto cultural, simbólico y psicológico, la importancia de tener un lugar donde ampararse, resguardarse, sentir seguridad y amor. Esto señala que la privación de un refugio es la mayor de las carencias materiales que un ser humano 
puede tener, ya que apela a la intimidad de su existencia y a la imposibilidad de habitar y ser acogido en el mundo, al excluir a las personas del cuido y todo el imaginario de lo que un hogar significa.

Por lo tanto, nuestra reflexión se ubica dentro de este último concepto, busca comprender las diversas problemáticas sin perder su rostro humano y parte de la filosofía como una aliada para cuestionar y visualizar el tema desde nuevas perspectivas. A pesar de que históricamente los registros investigativos se han centrado en el asunto de la vivienda, pareciera necesario comenzar a crear nexos y transgredir los límites entre los tres conceptos, pues al entenderlos de manera excluyente, tendemos a cegarnos por problemáticas aisladas y perder valiosos matices cuya complejidad debiera incluir temas como las migraciones, multiculturalidad, globalización, calentamiento global, salud mental y los modelos diversos de familia, por ejemplo. El habitar atraviesa todas las disciplinas y podría ser un punto de partida para comprender con mayor profundidad nuestros modos de convivencia en todas las escalas; siendo necesario trascender estas reflexiones y traducirlas en planes de intervención.

\section{El sueño del hogar. Sensibilidades, poesía y cuido}

La vivienda es un tema atípico fuera del urbanismo, la arquitectura y las ciencias sociales; $y$, mucho menos, un tema tratado filosóficamente, ya que desde un inicio se concibió como un asunto muy práctico y material. Aun así, la filosofía se ha referido a la arquitectura de maneras indirectas, al preocuparse por el significado del espacio y en especial al desarrollar los conceptos de "habitar", "edificar" y "construir" con un carácter metafísico y que, además, involucra la interacción del ser humano. El poeta y filósofo Ramón Xirau se ha preocupado por entender las profundas relaciones entre filosofía y arquitectura y, desde su poético lenguaje, ha determinado una importancia de filosofar sobre la arquitectura. Su cita dice así:

Puede sorprender, a primera vista, la cantidad de términos comunes a la Filosofía y a la Arquitectura. La Filosofía busca la sustancia, el fundamento; la Arquitectura funda para construir la casa, la morada, el templo; Filosofía y Arquitectura, parten, ambas de la materia para construir a partir de ella la casa interior o la casa exterior; Filosofía y Arquitectura ¿no andan conjuntamente en busca de las "moradas" íntimas del alma, de los "castillos del alma" para que sea posible nuestro habitar completo, nuestro habitar personal que es cosa del alma y del cuerpo al mismo tiempo? La Arquitectura edifica y, en su edificar, no deja de existir un fin humanista y aún ético. ¿No pretende la Filosofía edificar y aún ser edificante? Cuando Platón construye su mundo -mundo a su vez construido por el demiurgo, el arquitecto- y lo ve reflejo de una realidad superior -las Ideas, esencias eternas 
a ojos vistas-, lo construye para encontrar la habitación del hombre, el lugar del hombre, la morada donde pueda asegurarse de su dónde y su para qué.

Por lo menos esto hay en común: Filosofía y Arquitectura tratan de dar a los hombres su lugar en el espacio y en el tiempo. Toda metafísica tiene, sin metáfora, una Arquitectura; toda Arquitectura, sin metáfora, implica una visión del mundo o, más concretamente una metafísica. (Xirau, 1993, p. 142)

Y es que es necesario preguntarse: ¿Qué necesidad tenía el ser humano, desde tiempos antiguos, de hacer sus vasijas de barro con diversas formas y decoraciones más allá del propósito utilitario de servir como contenedoras de bebidas y alimentos? Y llevando esta idea al campo de la arquitectura, ¿qué necesidad tenemos de que la casa no solo pueda satisfacer nuestras necesidades de refugio y cobijo, sino que además la encontremos hermosa y agradable? Ambos argumentos suscitan una característica propia de la arquitectura; es una constante búsqueda de la sensibilidad. "Es preciso concebir para efectuar. Nuestros primeros padres sólo construyeron sus cabañas tras haber concebido su imagen. Esta producción del espíritu, esta creación es lo que constituye la Arquitectura ..." (Boulée, 1972, p. 243).

Si bien es cierto, la arquitectura y el urbanismo tienden a ser las disciplinas desde las cuales se enfoca el tema de la vivienda digna, valdría la pena recurrir a la visión crítica de autores como Bachelard, María Zambrano y Heidegger, ya que regularmente se les desprecia por la percepción de que sus aportes son quiméricos, ilusos y, por lo tanto, inaplicables. Zambrano menciona que "la ciudad es lo más creador entre las estructuras de humana convivencia” (Zambrano, 2001, p. 140).

En el caso de Bachelard, en su Poética del espacio, dedica muchos de sus argumentos a los temas del habitar, de la casa y de los lugares en los que nos sentimos albergados, porque justamente es sobre los espacios más íntimos, con los que hemos creado vínculos más fuertes y eso los hace un excelente punto de partida para aprender las artes de la interpretación; antes con lo que nos es más propio y conocido, que con los espacios hacia los que nos sentimos más ajenos. Si bien, las normas sociales y modos de vivir se han transformado substancialmente hasta llegar a la actualidad, es indiscutible que en la casa aún persevera, simbólicamente, el escenario más apetecido para el transcurrir de los eventos esenciales y sobresalientes de la vida, lo que le permite ser el ámbito más concreto para discutir el fenómeno poético.

Partir del concepto de casa es una idea muy sagaz que el autor aprovecha para acceder a las sensibilidades de su público lector y poder exponer desde ahí la poética del espacio, dejándonos llevar, luego, a los ensoñadores pensamientos poéticos que a través del espacio se despliegan. Además, por medio de la manera 
tan íntima en la que se hace referencia a la casa y sus componentes, se deja ver la interpretación liberada de objetividades obligadas y, por fin, sensata en cuanto a la singularidad con la que cada sujeto lee y reconoce sus experiencias espaciales. Las vivencias de la casa son singulares porque refieren a una pertenencia íntima y un objeto que es privativo de la vida del ser humano. Es el espacio en el que se desarrolla el núcleo familiar; ya sea unipersonal o con múltiples miembros. Significa, además, poseer un pedazo del suelo, ser dueño de un espacio que representa las necesidades específicas de sus habitantes, reflejo de las aspiraciones de la vida doméstica de un gran número de personas dentro de la sociedad. La casa, en muchos casos, también es el único lugar en el que se ha vivido o el que se ha heredado de generación en generación.

Es la encargada de protegernos del mundo externo, de consolarnos en momentos difíciles y de 'agazaparnos' en su interior. Por eso el filósofo menciona: "En efecto, ¿no encontramos en nuestras mismas casas reductos y rincones donde nos gusta agazaparnos?" Explica: “Agazapar pertenece a la fenomenología del verbo habitar. Sólo habita con intensidad quien ha sabido agazaparse" (Bachelard, 2000, pp. 23-24). Además, la casa representa, en parte, la cultura de nuestra sociedad, pero también una cultura familiar y una 'cultura personal' de nuestra propia identidad, lo que la hace necesariamente interpretable desde la subjetividad. Su singularidad no solo quiere decir que le pertenece a un cierto grupo de sujetos, sino que le confiere el poder de representar lo cotidiano, llevado a lo extraordinario, pues, en la regularidad de la vida, hay recuerdos y ensoñaciones que aumentan el valor emotivo de unos espacios de la casa sobre otros. Incluso, de entre los bienes que se pueden poseer, la casa es el bien que en la mayoría de los casos tiene el más alto contenido simbólico, ya que define las rutinas, modos de actuar y visualizar el mundo de quienes la habitan, determinando, de alguna manera, la forma de afrontar la vida.

Finalmente, es también una señal de estabilidad -o para los sujetos más frívolos, una representación del estatus-, el lugar de la seguridad física, de acceso a créditos hipotecarios, de mejor salud psicológica; pero, en general, un valioso capital que probablemente nos trascenderá después de nuestra muerte y será el legado de alguien más. La casa se convierte, entonces, en la forma arquitectónica y material de muchos de los anhelos existenciales del ser humano. Es, por tanto, el nicho en el que aprendemos lo que significa 'pertenecer' y 'arraigarse'; aprendizaje que se puede tener desde que se nace o lograrse por méritos propios en la adultez, como símbolo del 'poder superar la indigencia del ser' y confirmar nuestras coordenadas en el cosmos, del que todos formamos parte. 
Esta búsqueda incesante del ser humano, por sentirse protegido, cuidado e identificado con su espacio, es un asunto universalmente relevante y, por eso, debe recordarse lo siguiente:

Antes de ser 'lanzado al mundo' como dicen los metafísicos rápidos, el hombre es depositado en la cuna de la casa. Y siempre, en nuestros sueños, la casa es una gran cuna. Y el poeta sabe muy bien que la casa sostiene a la infancia 'inmóvil' en sus brazos (Bachelard, 2000, p. 30).

\section{El binomio casa-ciudad}

La palabra economía proviene de la voz griega, oikos-nomos, que vendría a ser "los códigos sociales y políticos de la casa", lo cual, ya de primera mano, nos invita a entender la casa como sistema básico de poder para la configuración de la sociedad. La casa viene a ser un engranaje de la ciudad, que es ciudad-estado (polis), escenario para la construcción del ser social y, por tanto, para la creación de una ética del actuar y convivir. De esta forma, se podría decir que la filosofía es producto de la ciudad y como lo dice Aristóteles en La Política, la ciudad, a su vez, es producto de un conjunto de casas.

Por este motivo, la casa se encuentra ampliamente ligada a la noción de ciudad; espacio que moldea nuestro modo de ser y ética ciudadana, constituidos desde la antigüedad -la casa y la ciudad- como lugares propios del ser 'digno de pertenecer' y 'digno de poseer'. Por ejemplo, el filósofo K. Ch. F. Krause señaló, desde inicios del siglo XIX, el derecho irrenunciable de toda familia a tener una casa, como un bien básico para la subsistencia, defendido por encima de la arquitectura política y religiosa que estaba muy de moda en su época, la importancia de la casa como núcleo para el desarrollo de la sociedad.

Luego, F. Engels logra elevar la problemática de la vivienda, rescatando la crítica a la vivienda indigna y precaria e, incluso, la ausencia de ella; en momentos en los que la industrialización y el surgimiento de las grandes ciudades requirió ensanchar las calles y destruir masivamente las viviendas del proletariado, dando origen a un problema crónico y a la aparición del arrendamiento como medida paliativa, acompañada por la indigencia, la exclusión social, la delincuencia y los primeros acercamientos a la importancia de la planificación para mantener la salud pública y el orden en la sociedad urbana.

Esto finalmente trajo un enraizamiento al estudio del asunto del habitar, desde las perspectivas económica, jurídica y social, y apareció el derecho de toda la ciudadanía a una vivienda digna en el artículo 25.1 de la Declaración Universal 
de los Derechos Humanos de 1948, apuntado a un ideal muy distante todavía en la actualidad, aún con los esfuerzos de concientización por parte de ONU-HABITAT (2014) y, a sabiendas de que más allá de seguir los objetivos de la Nueva Agenda Urbana, nos compete estudiar(nos) y traducir cada objetivo en acciones específicas y operables en nuestro país.

En Costa Rica, el derecho a la ciudad es inexistente, porque este se basa en la gestión territorial. Sin embargo, el país cuenta con un marco normativo de gestión de hace 50 años, una ley de planificación urbana y reglamentos de los años ochenta, los cuales promueven un modelo de ciudad muy difuso.

Así lo confirmó el abogado experto en derecho urbanístico, Mario Arce Guillén, en entrevista con UNIVERSIDAD, durante la XIV Bienal Internacional Profesional de Arquitectura (Núñez, 2018).

¿Cómo llegamos a vulnerar este derecho? El hábitat como concepto viene de la biología y su uso para describir la territorialización de los animales. Luego le designamos un carácter humano a razón del crecimiento urbano-cultural y la noción de la ciudad como el entorno propio de los territorios humanos. Esto permite el surgimiento de un campo relativamente nuevo, llamado "ciencias del hábitat" que trata de estudiarlo de manera transdisciplinaria, desde lo material y simbólico, la teoría sobre hábitat y la práctica de habitar.

Entonces, la arquitectura se ha valido de otras disciplinas para reinventarse, pero no siempre lo ha hecho con sabiduría. Vemos en la actualidad cómo las revistas promocionan el arte y la arquitectura como si se tratara de una marca de ropa o de un automóvil; sin embargo, pocas veces reflexionamos las consecuencias que esto trae a los conceptos que la arquitectura desarrolla. Foster menciona:

... por ende, tiende a ser absorbido como otro bien de consumo -un bien de consumo último. (Es por esto que importantes galerías, casas de subastas, revistas, museos, como beneficiarios de tal consumismo, promueven activamente el pluralismo.) Con la vanguardia reducida a un agente de innovación formal(ista) -a la «tradición de lo nuevo»-, se le aseguró al mundo del arte [y la Arquitectura] una línea ininterrumpida de productos que se vuelven obsoletos. Ahora, en lugar de la secuencia histórica, enfrentamos la formación estática: un bazar pluralista de lo indiscriminado reemplaza la sala de exhibición de lo nuevo. Como todo vale, nada cambia; y ésa (como escribió Walter Benjamin) es la catástrofe. (Foster, 2000, p. 11)

La búsqueda de la novedad se encuentra, con mayor frecuencia, presente en oficinas, áreas comerciales, restaurantes y aeropuertos, pues la arquitectura se ve 
motivada por un mayor presupuesto y el reconocimiento de una mayor cantidad de personas, a producir algo innovador. La situación contraria sucede con la vivienda, en donde, lastimosamente, se supone que la relevancia social es menor y sumado a eso, los presupuestos son más ajustados. Allí parece no haber lugar para la innovación, nos encontramos con un mismo conjunto de espacios (dormitorios, sala, cocina, patio, etc.) que se disponen como un producto más del montón. Los mismos promotores inmobiliarios han tomado la postura de que, "si este producto (residencia) se vende así, desde este concepto, ¿cuál es el objetivo de cambiarlo?”.

Así hemos llegado a tener un gran número de viviendas que se asemejan entre sí, que no tienen nada nuevo que contar, y que forman parte de un barrio en donde, a no ser porque la pintura, los acabados o la estructura envejecida lo delate, bien podríamos creer que una casa de hace 40 años y otra de hace 5 años fueron construidas en un mismo tiempo.

En muchos casos, no nos hemos preocupado por condiciones más allá de las funciones mecánicas y eléctricas, códigos sísmicos, planes de emergencia, o normativas municipales. Efectivamente, no se puede dejar por fuera estos parámetros; pero así como surgen sistemas constructivos nuevos acordes con los avances tecnológicos, debemos comprender que nuestro concepto de vivienda está obsoleto ante la realidad social de nuestros días. Lo cierto es que el núcleo familiar ya no consiste en el matrimonio tradicional; ahora nos encontramos con muchas personas que viven solas, familias monoparentales, familias que incluyen mascotas de distinto tipo, parejas sin hijos o personas con aficiones que requieren la adecuación de nuevos espacios.

Además, debido a que nuestra concepción del concepto de vivienda se ha estancado, hemos permitido que las normativas se mantengan sin cuestionar asuntos como la relación frente-fondo, que actualmente se rige acorde al aprovechamiento del suelo, pero que pone sobre la cuerda floja la posibilidad de tener baños con ventilación natural, cuando el baño es un espacio inevitablemente presente en una casa. La flexibilización de espacios, el aumento de las alturas libres, el mejoramiento del soleamiento y la ventilación deberían ser discutidos con mayor frecuencia y no desde el concepto de la "casa ecológica" o la "casa autosuficiente" como un mero eslogan publicitario, sino como una lucha política y social por ofrecer viviendas de calidad humana, en donde sea permisible que el sujeto usuario-habitante tenga un control sobre el aspecto final de la obra y no se vea obligado a resignarse a vivir bajo un concepto obsoleto.

El desarrollo de la ciudad no debería estar exclusivamente en manos del mercado, que se esfuerza por mostrar la movilidad, la sociedad y sus espacios públicos desde 
un artificio idealista, ajeno a las vidas del pueblo costarricense. Justamente la desvinculación casa-ciudad es la que hoy contribuye al crecimiento de la inseguridad ciudadana, el sobrepoblamiento incoherente con la infraestructura vial existente, el carrocentrismo y otros males que nos convierten en una sociedad cada vez más individualista que no sabe ni le interesa aprender a convivir. Esta es la parte que las inmobiliarias no nos comentan; a pesar de que resulta necesario que exista una relación mucho más cercana entre el Estado y el sector privado para lograr un equilibrio que lleve a esas fantasías de la mercadotecnia a reencontrarse con las metas país y la gente. No obstante, las situaciones nuevas intimidan y las personas prefieren negar la ciudad desde el interior de la casa, aunque esto implique convertir la ciudad en un ambiente violento y hostil. Nos invade una ceguera selectiva, en la cual, al adentrarnos en nuestras casas, como si de una caja fuerte se tratara (detrás de varios enrejados, portones, candados, puertas y tapias), nos encerramos también en nosotros mismos.

Ya la artista Dalia Ferreira lo hizo apreciar en el año 2014 con su muestra de arte digital, titulada Cuarentena, donde se retrata visualmente el encarcelamiento y angustia de la existencia en una ciudad que nos limita, pero en la que como en el juego de 'memoria', nuestra mirada se desplaza para encontrar parejas. Las vivencias de cada sujeto encuentran un par similar y queda expuesto que el mayor error sobre el ensimismamiento es pensar que cada cual es el ser único que lo padece; este es un problema de toda la población, que se hace visible gracias a la mirada crítica del espacio. Debemos admitir que, en la actualidad, vemos más hacia las ventanas del computador, que por las ventanas de nuestras casas. "La luz brillante homogénea paraliza la imaginación, al igual que la homogeneización del espacio debilita la experiencia del ser y borra el sentido de lugar" (Pallasmaa, 2006, p. 48).

La segregación residencial económica es un claro ejemplo de la manera en la que la ciudad y su configuración tienen una relación directa con la calidad del habitar, pues el hecho de que las personas deban desplazarse largas distancias para acceder a servicios básicos de salud, transporte, recreación y educación, entre otros, determina una disminución en sus oportunidades de desarrollo y acrecienta la concentración de la pobreza. La segregación produce desigualdad y aumenta el aislamiento social, y ocurre en las poblaciones en las que hay normalmente una gran cantidad de infantes y adolescentes; este fenómeno viene a convertirse en una transferencia intergeneracional de pobreza que amenaza con crecer en escala e intensidad. Por esto se ha dicho que "... las prácticas de dispersión de la pobreza o de proximidad física a clases altas serían la principal vía para mejorar las perspectivas de vida de los pobres" (Ruiz-Tagle, 2016, p. 39). 
Una evidencia del efecto del entorno sobre el comportamiento es la presencia de mayor delincuencia, deserción escolar y embarazos adolescentes, en zonas donde el estrato pobre es homogéneo en una gran extensión territorial. El entorno inmediato representa un cambio sobre el modo de pensar y habitar, tiene el poder de crear sentimientos de seguridad, pertenencia, estabilidad y cuido, que son importantísimos para impulsar la voluntad de mejorar, esforzarse y ambicionar con mayor ímpetu un hogar digno.

La casa es un refugio; el sentimiento del cuido, hecho tangible. Sin embargo, las casas por sí solas no reducen la pobreza. Cuanto más pronto entendamos la importancia de integrar esas casas en el tejido urbano, más fácil será que las personas con menos recursos se integren a la fuerza laboral, vivan mejor y eso les motive a ser más productivos y romper la herencia de la pobreza en sus hogares. El espacio actualmente rectifica, intensifica y reproduce una construcción simbólica de desigualdad. Sin embargo, el diseño del espacio tiene el poder de generar cambios en el comportamiento. "La autoconciencia es vista aquí como expresión de un comportamiento en condiciones de vida dadas. ... tiene un componente moral donde se destacan las normas y formas de comportarse el hombre ante el mundo circundante" (Ortíz, 2012, pp. 113-114). Nuestra identidad está asociada al binomio casa-ciudad. Es nuestro lugar (físico y simbólico) en el mundo y, aunque se tiende a olvidar, la vivienda es uno de los principales componentes de la ciudad, de manera que atender sus problemáticas es también resolver la ciudad.

\section{Los antecedentes de la pesadilla habitacional}

La historia de lo habitacional es también la historia de lo urbano. Desde finales del siglo XIX, con la Encíclica Rerum Novarum hubo una cierta noción de que el territorio debía estar al servicio de la comunidad, pero fue a través del funcionalismo y el racionalismo, descritos por Le Corbusier en la Carta de Atenas, que la arquitectura saca su mirada de las construcciones monumentales propias de la religión, lo militar y político, para acercarse a organizar el habitar. Plantearon una serie de soluciones que fueron válidas en su momento, para luego convertirse en un dogma que nos condujo a nuevas disfunciones del habitar; como la separación de la vida social por usos, la desaparición de zonas para estar y aumento de las vías de tránsito que no albergan más actividad que el movimiento de un punto a otro, así como la proliferación de intervenciones urbanas higienistas, impersonales y potenciadoras del aislamiento.

Este orden idealista, que si bien es cierto es útil para resolver la parte técnica del urbanismo, no contempla la dinámica urbana en toda su extensión social; el funcionalismo no es en sí una estrategia urbanística, sino un principio aplicable 
solo a casos particulares. Un resultado de estas premisas lo vemos reflejado en el Decreto 31730, el cual plantea la siguiente consideración en su cláusula 16:

Que los cuatro distritos que componen el Cantón Central de la Provincia de San José son áreas que enmarcan una serie de condiciones urbanas que han sido comprobados técnica e internacionalmente como causantes de mayores problemas sociales, a saber: emigración de inversiones, inseguridad, patologías sociales, crecimiento negativo de la población, abandono y deterioro edilicio, riesgo de pérdida de patrimonio arquitectónico o histórico declarado, pérdida o ausencia de espacios públicos de adecuada calidad, aprovechamiento ineficiente del espacio público, densidades de población muy bajas, congestionamiento vial y contaminación ambiental y un deterioro progresivo de la calidad de vida urbana. (Decreto 31730, 2004)

Y es que desde la metodología del "zoning" (segregación de las actividades en grandes bloques monofuncionales), en los años 60, la ciudad en el imaginario se percibía más compartimentada. El estilo de vida era el del vehículo y la casa de campo en la zona suburbana. Esto, por supuesto, nos condujo al "urban sprawl" o crecimiento horizontal. Hoy sabemos que necesitamos compactarnos, que el medio de transporte por excelencia debería ser caminar y en segunda instancia, los medios no motorizados; y así, con alrededor de diez veces más vehículos, la misma infraestructura de los años ochenta y una ciudad descrita como "dispersa, distante y desconectada" (Estado de la Nación, 2016, p. 42) nos damos cuenta de lo siguiente:

El 75\% de las viviendas ubicadas dentro del anillo es horizontal, es decir, rápidamente el suelo fue ocupado por edificaciones de uno o pocos pisos y en baja densidad. En consecuencia, la proporción construida en esa zona pasó de 49,7\% en 1986, a cerca de $82,1 \%$ en 2018 , lo que deriva en el agotamiento de la tierra libre cerca de los centros de las ciudades. Esta tendencia es notoria en las áreas donde se concentra la vivienda de interés social al sur y noreste de San José, así como al sur de Heredia. (Estado de la Nación, 2018, p. 159)

Por esto, a sabiendas de que para el 2050 un $70-80 \%$ de la población va a vivir en ciudad, tomando en cuenta el cambio climático y en miras a una industria de la construcción que es generadora de recursos, pero también de desechos que menoscaban nuestro camino a la carbono neutralidad, al igual que otras ciudades latinoamericanas necesitamos optar urgentemente por un "nuevo urbanismo". Este último concepto nace como respuesta al modelo expansivo y segregador de la segunda mitad del siglo XX en Seaside, Florida, Estados Unidos. Luego, en 1993, se hace el Congreso del Nuevo Urbanismo en Washington, DC, lo cual da pie 
a la Carta del Nuevo Urbanismo, de donde surge la metodología del transecto, smart code, urbanismo táctico, urbanismo participativo (charrette) y smart growth.

Los intentos que hemos realizado en este sentido no son nada despreciables. No obstante, el rechazo al PRUGAM (Proyecto de Planificación Regional y Urbana de la Gran Área Metropolitana) y al POTGAM (Plan de Ordenamiento Territorial de la Gran Área Metropolitana) implicó un gasto de recursos, no solo por la elaboración de dichos planes, sino porque las municipalidades también tuvieron que retomar la revisión de planes reguladores que se habían hecho en ese marco. Y luego, la parálisis en el desarrollo y aprobación de planes reguladores se tradujo en un estancamiento a las bases para la regulación del mercado de suelos y de los territorios en todas las escalas.

En efecto, la problemática con el aumento del costo del suelo, en la parte central del Gran Área Metropolitana, dificulta que el proceso de densificación de esta sea exitoso. Más bien, los proyectos habitacionales tienden a colocarse en la periferia, provocando un acceso deficiente a servicios, distancias más largas para trasladarse a los centros de estudio y trabajo, y un daño mayor al ambiente con suelos cada vez más impermeabilizados y un irrespeto general hacia los ríos y la vegetación.

En general, las regulaciones existentes se enfocan en trámites para la inversión en vivienda y equipamiento urbano, pero no existen herramientas de ordenamiento territorial que definan, con criterios técnicos, el rumbo de ese desarrollo y, sobre todo, que incorporen la variable ambiental de manera unificada y eficiente.

Aunque algunos esfuerzos específicos de elaboración de planes reguladores han considerado elementos ambientales en sus propuestas, "esto no se ha dado con un mecanismo unificado y de manera eficiente y viable. Sobre la marcha, el uso del suelo urbano expresa las tensiones entre el mercado y la preocupación por la sostenibilidad" (Estado de la Nación, 2018, p. 158).

Nuestro modelo de ciudad, su planificación e interacción con el ambiente puede generar problemas de erosión, contaminación de cuencas y desbordamiento de ríos; lo cual luego conduce a la inundación de casas que, aparte de poner en riesgo la vida de las personas, pueden dejar pérdidas y daños materiales muy difíciles de reparar y ocasionar un retroceso en la adquisición de este bien tan preciado. Tal ha sido la explosión de la problemática ambiental, urbana y habitacional que, incluso desde la iglesia, han surgido posturas como el Laudato $\mathrm{Si}$, que es una encíclica creada en el año 2015 y enfocada en el cuidado de la Tierra como 'la casa común'. A eso sumamos que, en el 2018 y actualizada en 2019, se expone un nuevo modelo de ciudad sostenible propuesto por la Agencia de Ecología Urbana de Barcelona en 
la Carta para la Planificación Ecosistémica de Ciudades y Metrópolis (2019). Así las cosas, aquella máquina de habitar colectiva, que sería la ciudad, vendría a ser una respuesta ampliamente reproducida, pero poco exitosa ante la complejidad de la realidad y rebasada por toda una serie de teorías urbanas más enfocadas en el ambiente y el ser humano.

Los últimos años de diagnósticos enfocados en la vivienda y el ordenamiento territorial nos han mostrado que, justamente, los espacios indefinidos son los que habría que estudiar, pues, a través del uso dado por la ciudadanía, narran lo impredecible del habitar y aleccionan sobre la necesidad de espacios flexibles, adaptables a necesidades diversas y confluyentes en usos mixtos del espacio.

Y es que el habitar no puede programarse. Esto es algo que Heidegger, como discípulo de la fenomenología de Husserl, tenía muy claro en textos como: "El ser y el tiempo", y "Construir, habitar, pensar", mediante los cuales viene a describir el habitar como un ideario de la existencia, acercándose más al concepto de "hogar", al hacer una distinción entre tener dónde alojarse (condición meramente material) y tener espacio para ser y habitar (condición que requiere reconocer el habitar como rasgo esencial del ser al que debemos sensibilizarnos para poder construir). Por esto, comenta:

En la actual falta de viviendas, tener donde alojarse es ciertamente algo tranquilizador y reconfortante; las construcciones destinadas a servir de vivienda proporcionan ciertamente alojamiento; hoy en día pueden incluso tener una buena distribución, facilitar la vida práctica, tener precios asequibles, estar abiertas al aire, la luz y el sol; pero: ¿albergan ya en sí la garantía de que acontezca un habitar? (Heidegger, 1994, pp.127-128)

Se puede extraer de sus ideas, que para que la vivienda sea digna, no solo debe construirse, sino que debe pensarse digna, de manera que la solución no debe ser urgente, sino reflexionada desde la comprensión del desarraigo, la alienación y la exclusión social, que resultan de no tener un hogar. De hecho, tanto Heidegger como Engels no hablan de la problemática de la vivienda, y más bien usan un lenguaje más desgarrador, refiriéndose al tema como una penuria de la vivienda, en la que la visión del ser humano, como máquina, lo desvincula de una vivencia activa del habitar. Por lo que la labor de profesionales de la arquitectura y urbanistas debieran ser no solo la de planificar y proponer, sino antes la de ser sujetos ciudadanos, habitantes, transeúntes y filósofos que, con oído atento y observación profunda, comprendan el engranaje de las dinámicas humanas que la ciudad representa. 
La ciudad se sitúa en la confluencia de la naturaleza y del artificio. Congregación de animales que encierran su historia biológica en sus límites y que al mismo tiempo la modelan con todas sus intenciones de seres pensantes, la ciudad, por su génesis y por su forma, depende simultáneamente de la procreación biológica, de la evolución orgánica y de la creación estética. Es a la vez objeto de naturaleza y sujeto de cultura; es individuo y grupo, es vivida e imaginada: la cosa humana por excelencia. (Lévi-Strauss, 1988, p. 125)

Heidegger además expresa cómo hay muchos espacios como las autopistas, fábricas, estadios, aeropuertos o hasta las centrales energéticas, que no constituyen una morada; pero sí son parte del habitar, pues habitar no consiste nada más en tener donde alojarse, es mucho más que eso. "Para el camionero la autopista es su casa, pero no tiene allí su alojamiento; para una obrera de una fábrica de hilados, ésta es su casa, pero no tiene allí su vivienda" (Heidegger, 1994, p. 127), es decir, que para poder 'habitar' no necesitamos las 'habitaciones' de una casa, pues el espacio-mundo es la gran habitación del ser humano y eso traslada las preocupaciones por el confort y el bienestar, que le eran propias a la vivienda como espacio privilegiado, al mundo, que es, en realidad, nuestro espacio para estar y existir.

\section{Modos de exclusión social}

Es curioso cómo cada vez que se organiza un evento orientado a ofertar soluciones de vivienda, confluyen personas con realidades abismalmente distintas, pero unidas por una misma aspiración. El anhelo de adoptar un pedacito de tierra, verlo crecer, llenarlo de vivencias y sentir la protección que proporciona saber que hay un techo para cubrirnos es una idea que supera la exclusión y la marginalidad; redescubre una especie de solidaridad y camaradería entre los asistentes a estos eventos. Independientemente de sus capacidades económicas, los "sin casa" nos percibimos como grupo; tenemos una gran meta en común y, por lo tanto, "somos de los mismos". Entre filas, charlas, exposiciones de proyectos, llenando formularios y solicitando evaluaciones de bonos y créditos, las personas comparten algunas historias de vida, preocupaciones, anhelos y desacuerdos con lo que el mercado ofrece.

En estos eventos, se percibe un distanciamiento entre las normativas urbanas, los derechos, los proyectos del Estado y los del mercado. Es un mundo de panfletos, con lonas impresas con visuales de edificios que levitan sobre el contexto, viajes de realidad virtual, promesas de una vida mejor, pantallas con imágenes de familias felices, cuotas, llaves en mano y números grandes con aclaraciones en letra pequeña. Grandes y pequeñas corporaciones saltan a hacer un despliegue de ofertas, mientras la vivienda digna, un "trending topic" en tiempos de campaña política, se convierte en una mercancía. Evidentemente, algunas empresas sabrán 
atender el tema con ética y responsabilidad social y, justamente, esto es algo que habría que añadir al concepto de vivienda digna, que no es únicamente aquella que cubre necesidades humanas esenciales, sino también la que nos permite vivir con dignidad mientras pagamos por ella, en una negociación justa y, por lo tanto, transparente, en una ciudad que integre nuestra casa en el territorio urbano.

En los últimos años, la incompatibilidad entre el Reglamento de Condominios, la Ley de Planificación Urbana y la planificación urbana regional ha permitido que los desarrollos más activos relacionados con la ciudad sean en construcciones que no reflejan beneficios para la colectividad, porque son de carácter cerrado, en urbanizaciones y condominios que se enclaustran produciendo el conocido efecto burbuja, e inhabilitan la continuidad vial y, además, contribuyen a la dispersión de la ciudad. Los condominios, que comienzan a generarse inicialmente en zonas como Barrio Dent, Los Yoses, Escalante y Escazú, surgieron desde grupos de personas normalmente pensionadas, cuyos hijos ya se han marchado de la casa, por lo que se les hacía más difícil el mantenimiento del inmueble y les generaba sensaciones de inseguridad a raíz de continuar viviendo a solas en propiedades grandes. Posteriormente, aparece un mito que hasta la fecha ha sido difícil de erradicar, el cual se asocia con el condominio como respuesta a la inseguridad percibida y a la delincuencia, en donde la muralla y su capacidad de restringir, excluir y negar el paso, se convierte en la gran aliada para "protegerse".

Sumado a esto, el condominio, como símbolo de estatus social y prestigio, se convierte cada vez más en uno de los grandes favoritos de la población con mayor capacidad adquisitiva y en una añoranza de los que menos tienen. Se ha producido, con muros de piedra y agujas, una separación tangible de las clases sociales; y nuestro hábitat que es sensible a todo esto, lo refleja en una categorización de nuestro valor como personas y ciudadanos. Por ese motivo, al separar los estratos, se intensifica la incapacidad de sociabilizar, se crean grupos con serios resentimientos sociales, mayor conciencia de las diferencias y repercusiones culturales en cuanto a la insensibilidad y apatía hacia las necesidades del otro. Una adulta mayor comenta (comunicación personal, 2019): "Diay... los ricos de juntan entre ellos y los pobres nos juntamos porque no queda de otra. No me quejo, no es que quiera vivir como rica, sino disfrutar de las mismas oportunidades. Si no, ¿cómo salimos de esto?"

Ciertamente, prestando atención a conversaciones de la vida cotidiana, se puede denotar que las personas de clase media y media-alta tienen dificultades para aceptar que los de menos recursos reciban "gratuitamente" una vivienda con las mismas características que lo que ellos compran. Un entrevistado (comunicación personal, 2019) lo dijo así: "... ni soy tan pobre para que me den el bono completo, 
ni tengo suficiente plata para que me den el crédito que quisiera. Porque a los pobres sí les dan todo gratis".

Un estudio realizado por el Instituto de Estudios Sociales en Población de la Universidad Nacional (IDESPO-UNA) señala a la vivienda como la principal causante de la sensación de pobreza o la autopercepción del "ser pobre". "El estudio indagó sobre las características principales que hacen que una familia sea considerada pobre. Los entrevistados enumeran, en su orden: carencia de vivienda, falta de trabajo, falta de dinero y escasez de alimentos" (Molina, 2004, párr. 4). Siendo la carencia de vivienda una de las principales características de la pobreza, este también viene a ser el camino para su aumento. La atención a la clase media en cuanto al acceso de vivienda está asociada a que ese estrato medio no desaparezca, ya que si lo hace, será aún más difícil atender el derecho a la vivienda en una población cada vez más llena de necesidades y resentida por su declive socioeconómico. La otra cara de la moneda se presenta en las palabras de una madre adolescente (comunicación personal, 2019): "Son años y años de lucha, jalando latas, levantando postes a escondidas para agarrar corriente y así con el agua y con todo. Tenemos que vivir y hay que arreglárselas".

Además; hay que recordar que la mayoría de las personas en vulnerabilidad no acceden al Bono Familiar de Vivienda porque desconocen en qué consiste o cómo gestionarlo, lo que, por supuesto, contribuye al crecimiento de los precarios. De fondo lo relevante es transformar, más que erradicar, pues el precario como tal representa para ese conjunto de personas su hogar y escenario de los vínculos afectivos. Tratar el concepto de precario como si ese espacio en sí fuera la causa de los males de la ciudad y cargarlo de toda esa negatividad no resulta de gran ayuda. Estas personas han contrariado muchos obstáculos, levantado casas con el trabajo de sus manos en donde no había nada y, aunque no cuenten con la formación de un urbanista, han producido un hábitat basado en criterios de desempeño real que incluso a veces tiene más vida, dinamismo y cohesión social que la propia ciudad.

Ese poder histórico de los precarios tiene su lugar en la identidad de cada uno de sus habitantes y las luchas que han dado en conjunto. ¿Cómo nos sentiríamos si el lugar en el que crecemos y aprendemos es visto con mirada despectiva como algo que hay que erradicar como si de una enfermedad se tratara?

Lo que pasa también es que la empatía no se vive a lo lejos, hay que caminar, agarrar el bus y compartir con gente de todas partes y de todas las edades. Hace rato sabemos que la participación ciudadana permite reconocer de primera mano las problemáticas urbanas inmediatas; en lo que quedamos debiendo es en llevar 
el proceso a largo plazo, dar seguimiento y no dejar en el olvido a las comunidades después de finalizado un proyecto, lo que sería una garantía de éxito y aprendizaje.

Curiosamente, pareciera más fácil lograr el éxito de las intervenciones urbanas en estas zonas. La experiencia nos dicta que, en general, cuanto más bajo es el estrato socioeconómico, hay más densidad y uso del espacio público; mientras que en áreas menos densas, hay más opciones de espacio público con mejor mantenimiento, pero se le saca un menor provecho e incluso se le ve con indiferencia. Lastimosamente, el financiamiento de los espacios de uso común con carácter social y cultural en los proyectos habitacionales de interés social se ha confundido con un gasto, cuando en realidad es una inversión que ayuda, en gran medida, a garantizar el éxito. El concepto de 'COMPLOT' entendido como la promoción de la comunidad sumada al desarrollo de los Planes Locales de Orden Territorial (PLOT), una estrategia utilizada en Guatemala según Ferrufino \& Grande (2013) es un modo para forjar el sentido de pertenencia, muy distinto al de posesión. Es un sentimiento de adentro hacia afuera (hacia un lugar o grupo) que incluye componentes afectivos y de compromiso. Un modo de accionar que no consiste en ser miembro y no se construye a través de la legalidad, sino de las luchas compartidas y la convivencia.

Hemos caído en el error de pensar que el espacio público es el espacio urbanizado, pero eso son suburbios. El espacio público es el que viene de la integración, de un pensamiento en pequeña escala que facilita la gestión. El cuido de las zonas verdes, sentirse parte de una comunidad, preocuparse por el bienestar de todas las personas son cosas que solo llegan a las personas que atraviesan en conjunto procesos de toma de decisiones, defensa y sana apropiación de su territorio. En una entrevista Yerlin Montero, líder comunal del asentamiento El Relleno de Pavas (comunicación personal, 2019), dijo algo revelador: "llegar al barrio debe ser como llegar a la casa compartida". Este empoderamiento que surge de concebir los proyectos como producto del esfuerzo propio, y no como "regalo estatal", es lo que da sostenibilidad a través del tiempo.

Por eso, crear capacitaciones para las familias con acompañamiento profesional en los procesos de gestión, hacerles saber a los gobiernos locales que la tierra es un activo para el desarrollo social y crear modos de certificar el aprendizaje por experiencias. Esto podría servir para que desde los mismos habitantes surjan las propuestas y la fuerza de trabajo, para hacer la transformación del espacio de una lógica de carestía a una lógica de ciudad para el desarrollo de las personas.

Se tiende a pensar que las personas que viven en precario tienen más facilidad para convivir en vertical, debido al hacinamiento; pero la realidad es que, en mucho casos, ansían tener casa propia justamente pensando en desligarse de los miembros 
de la comunidad que consideran nocivos o conflictivos, por lo que si no se presta atención al saneamiento de la convivencia comunal, se da pie a proyectos infructuosos en los que más que una red de apoyo vecinal, se crean nuevos sitios para la marginación, la violencia y el rezago socioeconómico. Aquí las palabras de un hombre desempleado (comunicación personal, 2019): "Nosotros solo podemos vivir donde hay ríos y derrumbes porque aquí sí nos dejan. Yo no escogería vivir tan alejado, ni convivir con toda esta gente. Esto no es lo que yo quiero, pero es lo que puedo hacer".

Por otro lado, parece importante respaldar las propuestas de vivienda con la búsqueda de alternativas de empleo estable y cercano, ya que, de otra manera, se dificulta, aún más, convencer a las familias, que siempre adquirieron los servicios públicos de manera "gratuita", de comenzar a pagar recibos de agua, luz e inclusive recibos colectivos (para la iluminación), seguros para la vivienda e impuestos de bienes inmuebles.

Al inicio nos enfocábamos únicamente en satisfacer las necesidades de familias de bajos recursos, pero poco a poco hemos caído en cuenta de que los servicios se deben extender al ordenamiento territorial, el análisis del comportamiento de los asentamientos humanos y las necesidades de las clases medias que se habían quedado a un lado.

Existen pocos desarrollos habitaciones destinados a la clase media; es decir, hay demanda, pero no hay oferta. Las personas en algunos casos se muestran reticentes ante la prohibición de vender o alquilar la casa por un periodo de 10 años, no logran adecuar sus aspiraciones y necesidades a los proyectos pensados para otras familias con menores ingresos, tienen sus ingresos comprometidos en una serie de deudas que les impiden solicitar un crédito, pues el bono les es insuficiente para construir su vivienda, ya que siendo inversamente proporcional al ingreso de la familia, la necesidad de un crédito se vuelve imperiosa. Un vecino de Guanacaste, comparte (comunicación personal, 2019): "Usé el bono y al tiempo vendí unas herramientas para poder comprar el piso por mi cuenta. Me lo comenzaron a instalar, estando la casa ya casi terminada y cuando el inspector vino me dijo que eso era prohibido. Quería que yo le pagara unas platas aparte, porque si no me iba a denunciar".

En este momento, hay miles de viviendas que requieren reparación; sin embargo, el proceso para calificar por un bono, las tramitologías y permisos se convierten en una carga económica y un proceso que la mayoría describen como una vorágine de primas elevadas y altas tasas de interés, que lo convierten en un proceso sumamente estresante. Así lo afirma una mujer embarazada: "Solo conseguir la prima para la casa, ya es casi imposible. Casi no hay opciones porque el negocio está en la vivienda de bien social y en las casas de lujo; no hay puntos medios" (comunicación personal, 2019). 
Ideal sería que el mercado de la vivienda no estuviera mediado por la noción de si se califica o no; sabemos que todas las personas y familias califican porque la vivienda es un derecho en donde no puede existir exclusión. Sin embargo, es un mal necesario para levantar antecedentes que ayuden a predecir nuevas y mejores soluciones. De otra manera, perdemos demasiado el control y la ciudad crece libremente con todas sus patologías. Por ejemplo, ya hemos visto que los patrones de urbanización insostenibles del área metropolitana se están replicando fuera del Valle Central en las ciudades intermedias, lo cual, aunado a la poca rigurosidad en cuanto a trámites e inspecciones en las zonas rurales, es otro modo de exclusión muy serio, porque pone en peligro la vida.

Ante la falta de opciones para hacerse de una casa, vemos cómo se levantan obras de manera empírica en muchos poblados, en donde con la mejor de las suertes hay, si acaso, un albañil experimentado atendiendo los procesos constructivos. Estas prácticas ponen en riesgo la vida de las personas, ante sismos, colapsos estructurales o fallas eléctricas y mecánicas.

Los desarrolladores de proyectos habitacionales bien podrían tener obligación de adecuar un porcentaje de sus proyectos, para la construcción de obra social, equipamiento urbano y otras infraestructuras complementarias. No parece que la solución tenga que ver con evacuar a las personas del lugar en el que han echado raíces (a menos de que se trate de zonas de riesgo para la vida humana o el ambiente), sino más bien de transformar el sitio en el que ya se encuentran e integrarlas al tejido urbano hasta que el límite psicológico entre "mi lado y el del otro sujeto" se difumine. Un joven encargado de controlar el ingreso a algunos precarios en la zona de Los Diques, Cartago, menciona: "Yo estoy de mi lado. Si no se meten con nosotros, aqui nos quedamos tranquilos. A ellos les estorba, pero se jodieron porque ya de aquí nadie nos saca" (comunicación personal, 2019).

En el 2011 la Defensoría de los Habitantes había confirmado denuncias debido a que las listas de personas beneficiarias para el bono de vivienda estaban siendo emitidas por las empresas desarrolladoras, sin contar con una fiscalización sobre los criterios de selección. Son más de 20 los sitios oficiales en los que se puede solicitar el bono, sin embargo, debido al desconocimiento y temor de las personas hacia los trámites por enfrentar, han sido los mismos entes proveedores de las empresas constructoras los que asumen la tarea de gestionar el bono, de manera que, muchas veces, no se ha hecho una valoración adecuada de los casos por parte de las entidades autorizadas, las cuales confían en la lista que se les brinda y, en ocasiones, terminan beneficiando a personas, sin verificar la veracidad de sus necesidades. Así nos lo cuenta un agricultor: "Nosotros lo quisimos intentar, pero todo se complica. Las empresas siempre quieren que uno les retribuya algo por meterlo en la 
lista y después, si el proyecto se atrasa, hay que pagarles para que lo mantengan en la lista y así se lo llevan... La plata no da para tanto" (comunicación personal, 2019).

Claramente, hay una gran diferencia entre la ayuda con trámites y la potestad para definir listas. Estas decisiones delegadas en los grupos desarrolladores implican un conflicto de intereses, ya que, para quienes desean ejecutar la construcción, es mucho más tentador levantar requisitos y, por lo tanto, reducir la rigurosidad del proceso de priorización con el que se debiera trabajar. Esto da por resultado la recepción de beneficios a personas que ya cuentan con una vivienda, el uso no ético del bono por parte de empresas constructoras y, en algunos casos, de los propios beneficiarios, que utilizan los bonos como una ayuda adicional para construir casas de lujo o con acabados muy superiores a las de otras familias en supuesta igualdad de condiciones, la construcción de viviendas de bono como estancias para vacacionar o, inclusive, casas que en vez de beneficiar y aminorar las cargas de grupos familiares que viven en la informalidad y en riesgo social sirven a una sola persona con capacidad ahorrativa y de crédito.

No puede, entonces, la conformación de listas de beneficiarios constituirse en un negocio per se, o bien, la construcción de proyectos de vivienda, una inversión vista desde el punto de vista de su rentabilidad para la empresa, dejando de lado que esta es una labor delegada por el Estado, que pretende hacer efectivo un derecho humano: el derecho a la vivienda digna (Defensoría de los Habitantes, 2012, p. 55).

En efecto, esto, además, genera exclusión hacia las familias con menos recursos porque al ser los grupos desarrolladores quienes conforman las listas, puede suceder que les manipulen solicitando pagos adicionales a cambio de la inclusión. Por esto, es necesario que la gran fortaleza de las instituciones públicas se relacione y cree alianzas con la empresa privada; crear incentivos que convenzan a la empresa privada de hacer mejoramiento barrial, y apoyar a las empresas que sí tienen vocación humanista, en las que los objetivos sociales son más importantes que las ganancias económicas y, en donde, sea el gobierno el que marque la pauta sobre los proyectos y su ubicación.

El hombre, en cambio, está casi permanentemente necesitado de la ayuda de sus semejantes, y le resultará inútil esperarla exclusivamente de su benevolencia. Es más posible que la consiga si puede dirigir en su favor el propio interés de los demás, y demostrarles que el actuar según él demanda redundará en beneficio de ellos ... No es la benevolencia del carnicero, el cervecero o el panadero la que nos procura el alimento, sino la consideración de su propio interés. No invocamos sus sentimientos humanitarios, sino su egoísmo; ni les hablamos de nuestras necesidades, sino de sus ventajas. (Smith, 1996, p. 45-46). 
$\mathrm{Ni}$ el cemento chino ni los prototipos ahorrativos de vivienda van a constituirse como el punto de giro para aumentar significativamente las oportunidades de tener casa propia, porque esas "soluciones" terminan cayendo dentro del mismo sector privado que coloca esa ganancia diferencial a su favor. Además, sabemos que la casa es un asunto multidimensional en donde un cambio en el costo de un material no es determinante, al lado de una estrategia de política pública.

Para familias de clase media y para jóvenes, obtener un subsidio o crédito del Sistema Financiero Nacional de Vivienda (SFNV) se ha convertido en una pesadilla que va más allá de la burocracia y la respuesta lenta de las instituciones; pues en este panorama económico solamente el costo de la vida en general, ya se encarga de cortar la capacidad de ahorro. Por ejemplo, para una familia de clase media, al pedir una hipoteca o consultar con cuánto debería endeudarse, se les pide un 20-25\% del ingreso familiar. Sin embargo, para las familias que apenas se asoman al rango de lo que llaman clase media, el dinero que gastan mensualmente entre alimento y transporte, ya representa un $20 \%$ de su ingreso. Una mujer josefina aclara: "Nosotros queremos construir y nos alcanzaría perfecto, si no estuviéramos alquilando y ya tuviéramos el terreno" (comunicación personal, 2019).

El hecho de pagar un alquiler ya es, en sí, un golpe económico fuerte. Urge en ese sentido, replantearnos la ley de arrendamientos para regular los abusos y evaluar la calidad de esos espacios que muchas veces no son dignos, pero se cobran caro únicamente por su ubicación. Comenzar a visualizar a ese gran grupo de familias inquilinas como potenciales aliadas interesadas en la vivienda cooperativa y el 'leasing habitacional' sería un punto de partida para que dejemos de construir casas sin gente y dejar a la gente sin casa.

El desalojo, como uno de los momentos más vulnerables para una familia que finalmente reconoce su imposibilidad para pagar un alquiler, tiene mucho potencial para convertirse en una situación violenta, abusiva y degradante; especialmente traumática en la infancia y con graves consecuencias para la familia que tiene que avenirse a buscar y costear un nuevo lugar, arrimarse a otros familiares, contribuir a perpetuar el uso de cuarterías o levantar un rancho para subsistir. Existen caseros que en este tipo de situaciones se toman la potestad de decomisar electrodomésticos y otros bienes, maltratar, amenazar y solicitar favores; a razón de su supuesta ventaja como dueños del inmueble que alquilan. Dignificar el desalojo y luchar porque no suceda de manera arbitraria es el inicio para hacer justicia a las consecuencias psicológicas de perder el hogar, que van acompañadas de sentimientos de inestabilidad, desarraigo, indefensión y abandono. 
La vivienda, que aparece en la Declaratoria Universal de Derechos Humanos y más recientemente en el Pacto Internacional de Derechos Económicos, Sociales y Culturales de la ONU (1966), es uno de esos derechos que se han obviado al punto de volverse casi invisibles. Tal vez habría que haberle dado, desde un principio, un cuerpo institucional y normativo, similar al del acceso a la salud y a la educación, en donde entre todo el pueblo costarricense cotiza y obtiene cuestiones tan complejas y caras como una cirugía, aunque haya otras personas con ingresos mucho mayores. Esa gran bolsa colectiva podría servir para regular los altos precios de los alquileres, que no son más que una consecuencia de la asincronía entre la oferta y la demanda, y para lograr que los proyectos de vivienda tengan mayor relación con los servicios de transporte público y las áreas donde se concentra el trabajo o las universidades, según el caso, porque sería una entidad pública la que, con base en las cifras socioeconómicas y diagnósticos urbanos, definiría las mejores ubicaciones.

Hasta ahora, una respuesta un poco más sensata ha sido comenzar a pensar en subsidios de origen público-privado, la idea de fomentar incentivos fiscales y urbanísticos para la inclusión de personas de todos los estratos en los proyectos y procurar los usos mixtos. También la proliferación de eventos culturales, académicos y profesionales destinados a crear conciencia social sobre estos temas es una respuesta coherente, ya que sabemos que ninguna solución encontraría cabida sin antes sensibilizar a las personas en los altos mandos sobre la vida urbana y la necesidad de pensar desde la colectividad

No obstante, tenemos mucho por hacer a nivel de comunicación, pues a pesar de la claridad de la información en sitios web y centros de atención al cliente, sigue faltando mayor difusión, pues las personas de clase media en muchos casos ignoran la existencia del bono diferido y los programas de ahorro-bono-crédito, entre otros.

Una de las preocupaciones es la de no poder asumir el costo de la deuda, una vez que se acaba el aporte del bono diferido. A los bancos también les preocupa recuperar el dinero, si sucediera algún desastre natural o las familias cayeran en la inestabilidad económica a causa del desempleo por largos periodos, por lo que elevan las tasas para aminorar estos riesgos. "Casi siempre un trabajo llega primero que una casa, pero si uno pudiera trabajar teniendo la motivación de que realmente es factible hacerse de una casita en un periodo corto; ahí la cosa cambia. Es que la casa es un arma de doble filo, porque también puede ser una deuda de por vida", comenta un mensajero alajuelense (comunicación personal, 2019).

También sucede que, cuando se enfrentan a la compra de lote y construcción, desconocen que deben contar con el visado municipal del plano de catastro, el lote 
debe contar con servicios de evacuación de aguas negras y pluviales, electricidad y debe estar en una zona topográfica adecuada; verificar ante la municipalidad que el lote cumpla con los requisitos de la Ley de Planificación Urbana, buscar un profesional de ingeniería o arquitectura que haga los planos y el presupuesto y, además, tramitar permisos ante el CFIA (Colegio Federado de Ingenieros y Arquitectos de Costa Rica).

En otros casos, el proceso no tiene éxito porque las personas desconocen las limitantes del bono. Tal es el caso de una funcionaria que declara: "Yo comencé el proceso del bono y a recopilar documentación para al final darme cuenta de que sí calificaba, pero no lo podía usar para cancelar la hipoteca; perdí el tiempo por no saber, ni preguntar" (comunicación personal, 2019). O este otro caso de un vecino de Heredia: "No califico porque ya me dieron el bono una vez. Lo que pasa es que venía con un crédito y como no lo pude seguir cancelando, perdí la casa y la oportunidad de pedir el bono ahora que más lo necesito" (comunicación personal, 2019).

También, en el caso de la compra de una casa, gran cantidad de personas desconoce que debe contar con una valoración por parte de un profesional en ingeniería; que requiere una carta de compra-venta por parte del dueño del inmueble que contenga el valor y esté firmada; que la vivienda debe tener los impuestos municipales al día y estar en óptimas condiciones; que debe contar con un plano de catastro y un documento oficial donde aparezcan los dueños que ha tenido la propiedad hasta la fecha. A excepción de los casos de extrema pobreza en los que se pueden hacer estos rebajos del bono, las personas no saben que deberán cubrir los gastos de avalúos, estudios de suelo, planos, inspecciones, gastos legales y administrativos, lo que genera atrasos, repetición de procesos, desconfianza y estrés en solicitantes. Ello, sumado al tiempo que pueden tardar las entidades autorizadas en reportar errores, formalizar las gestiones y liquidar el crédito, implica una sensación de zozobra e impotencia que les hace darse por vencidos o vencidas.

"Todas esas formalizaciones toman mucho tiempo... son un desgaste, pero son necesarias, si uno quiere que lo ayuden" (comunicación personal, 2019); así lo decía una pensionada mientras esperaba que atendieran a su hijo en una de las cooperativas autorizadas para obtener bono de vivienda. A este desconocimiento hay que agregar la falta de empoderamiento. Hay un temor a denunciar las prácticas corruptas o negligentes por parte de las empresas constructoras y a exigir informes y pruebas sobre la manera en la que se invierte el dinero del bono, con la finalidad de que no se abaraten costos a expensas de la calidad de los materiales o, también, corroborar que se respeten las buenas prácticas en el proceso constructivo. 
Actualmente se está incurriendo en un doble gasto de recursos públicos: se otorgan bonos en proyectos de vivienda con el fin de dar solución de vivienda a las personas de escasos recursos económicos y, en el corto plazo, se presentan problemas constructivos en los proyectos que requieren de una nueva inversión para solucionarlos. (Defensoría de los Habitantes, 2018, p. 166)

La casa social debe hacerse con la misma calidad humana y compromiso que la de lujo. No hay necesidad de hacer evidente que se trata de viviendas de bien social. Es necesario quitar el estigma de relacionar el bono con vivienda de baja calidad, pues esto finalmente hace que el terreno pierda plusvalía. También, en otros casos, las empresas constructoras no entregan el juego de planos final a la familia, por lo que años después cuando requieren hacer alguna obra de remodelación o la casa presenta alguna deficiencia, se ven obligados a gastar más recursos porque desconocen la ubicación y detalle final de las instalaciones eléctricas, mecánicas y estructurales. Las familias normalmente también desconocen que hay una serie de requisitos más detallados que los solicitados por el BAHNVI, que dependen de cada entidad autorizada para tramitar el bono y aumentan la cantidad de gestiones que deben hacer, lo que genera la percepción de que el proceso se vuelve más complicado conforme se avanza.

Hacerles ver su derecho a estar vigilantes de la calidad con la que se les atiende y se construye la casa es una labor tan primordial, como la necesidad de que busquen el respaldo de un contrato sano que les permita defenderse ante cualquier abuso. Además, cabe recalcar que servicios como la disponibilidad de agua o electricidad, propios de nuestra propuesta de ciudad, afectan la obtención de bono o préstamos para vivienda, de forma que las familias en algunos casos tienen que incurrir en procesos adicionales para llevar estos recursos hasta la comunidad en la que se va a ejecutar la obra.

Dejando de lado la situación en la ciudad, otro claro ejemplo es el caso de las tierras indígenas, en las que recurriendo a la violencia, se ha despojado a las personas de sus raíces y, con ello, de los vínculos que como comunidad construyeron, a causa de personas inescrupulosas que venden las tierras a terceros para atender sus propios intereses, a pesar de ser supuestas representantes de los pueblos indígenas.

Siguen sin desarrollarse programas y políticas adecuadas a las especificidades culturales de los pueblos indígenas; no existe un plan nacional de vivienda indígena, tampoco un programa particular de capacitación y formación profesional, ni un plan de desarrollo productivo sostenible que les ayude a impulsar las actividades en los territorios y contribuya al mejoramiento de sus condiciones de vida y trabajo. (Defensoría de los Habitantes de la República, 2018, p. 131) 
Y si la casa es el lugar en el que se está la mayor parte del tiempo, habría que tomar en cuenta, por ejemplo, a las personas en situación de cárcel que se supone están en ese sitio para rehabilitarse y reformarse, en cuyo caso el hacinamiento, la ausencia de zonas verdes y recreativas, la mala ventilación e insalubridad juegan en contra de la dignidad y el cuido que requiere un ser humano para decidir transformarse. Esto no implica brindar lujos, pero sí el reconocimiento de que el entorno físico inmediato altera el modo de pensar y actuar, de manera que si se vive en la cárcel, el propio recinto debería representar la base del cambio para esa persona.

También, "se continúan invisibilizando las necesidades de las personas con discapacidad en la asignación de los subsidios para la compra de vivienda (bono de vivienda)" (Defensoría de los Habitantes de la República, 2018, p. 145).

Tomar las riendas en cuanto a la vivienda en nuestro país también implica diseñar mayor cantidad de alternativas de modelos de vivienda de interés social para personas adultas mayores y personas con discapacidad, y no solo pensar en la casa como tal, sino también en la interacción con el mobiliario; hacer las adaptaciones necesarias para las discapacidades más comunes y, además, atender cada caso particular para contribuir al levantamiento de un buen repertorio de opciones. Es caer en cuenta de que las mujeres jefas de hogar son quienes presentan mayor grado de asistencia y disposición a colaborar cuando se realizan procesos participativos relacionados con el mejoramiento barrial o la vivienda. De modo que si una mujer está en posición de ser escuchada, de participar en política pública, de ser líder en su barrio o en una institución, debe sacar el mayor de los provechos de esas oportunidades para ver por las demás mujeres que viven más intensamente la exclusión.

Así lo han demostrado la Red de Mujeres Rurales, quienes tratan de que cada vez sean más las mujeres dueñas de propiedades agrícolas, que de esta manera logren su emancipación de situaciones violentas, mantener a su familia y procurarse una fuente de alimentos. Esta lucha por la tenencia de la tierra se traslada a la ciudad a través del cooperativismo y el liderazgo femenino de las comunidades con mayores grados de violencia doméstica, ya que "... hay un riesgo más; que dicha tenencia sea adjudicada únicamente a favor de los varones de la familia pese a que, en caso de conflicto, las mujeres suelan conservar con ellas a las criaturas" (Paniagua \& Salgado, 2012, p. 31).

Esta no es solo una lucha contra la planificación y diseño androcéntrico de los servicios sanitarios en donde el cambiador de pañales solamente está en el baño de mujeres o por los espacios recreativos que no deberían ser solo campos de 
futbol o actividades predominantemente masculinas: es también la lucha por las generaciones venideras.

"Las mujeres en comparación con los hombres son quienes más hacen uso de la ciudad, por lo tanto son quienes más la padecen” (Paniagua \& Salgado, 2012, p. 73). Pero, al planear el transporte público para las actividades necesarias y reducir la frecuencia para las actividades opcionales, la mujer trabajadora que debe ir a dejar a sus hijos a la escuela queda penalizada.

La ciudad ha sido pensada desde los planos, pero hay que pensar cómo esas decisiones afectan en pequeña escala y en la vida cotidiana. Hay una relación directa entre el entorno físico y el entorno social. Tal y como lo expone el antropólogo Clifford Geertz (1973) cuando se refiere al concepto de descripción densa, es necesario prestar atención a lo particular, pues las cosas pequeñas hablan sobre grandes asuntos. En el urbanismo sería Jane Jacobs (2011) quien nos recuerda que hay que hablar de lo "corriente" y "vulgar", pues lo que es excepcional, es excepcional; pero nuestra vida ocurre en lugares corrientes y vulgares, por lo que debemos ocuparnos de ellos. Hay que tomarse el tiempo de mirar lo ordinario e integrar las experiencias de vida en el diseño de soluciones habitacionales. A mayor equidad, mayor intercambio y esto es lo que nos empodera para luchar contra el urbanismo de la gentrificación, la exclusión y el miedo.

Las viviendas deben ser soluciones reales; deben brindar todas las cualidades espaciales y urbanas para que sea posible crear un hogar en ellas y deben dejar de ser estrategias para desentenderse ante el fracaso de un sistema que no logra combatir las problemáticas reales y prevenir su reproducción.

\section{Conclusión. La lucha por la casa propia: Agenda de discusión y acciones para ir por el sueño}

Si realmente queremos una sociedad que le dé las mismas oportunidades a todos los sectores, la vivienda es un componente crucial. En los últimos años la creación de movimientos de iniciativa ciudadana como 'De la Mano con la Calle', 'Cooperativa de Vivienda Fuerza, Unión y Destreza por Ayuda Mutua' (Coovifudam), 'San José ¿Cómo Vamos?', 'Chepe se Baña’ y ‘Un Techo para mi País'; entre otros, vienen a dar aliento a la lucha por un habitar más digno. A esto se suma la oficialización del Plan Integral de Movilización Urbana Sostenible (PIMUS), el lanzamiento de la Plataforma Digital APC Requisitos y la aplicación móvil llamada "Mi Bono en Línea", así como la ratificación de la directriz para permitir a las familias LGBTIQ acceder al bono familiar de vivienda por medio del BANHVI a finales del 2018. 
La idea de hacer mejoras a través del Bono Comunal, enfocarnos más en la persona para modificar el sistema a su favor, dejar el enfoque viviendista que ve las viviendas como un número, para comenzar a explorarlas en lo cualitativo y como un aporte al paisaje urbano y sus itinerarios, empieza a figurar una ciudad que en camino hacia una construcción resiliente. En este aspecto, los planes reguladores juegan un rol transcendental, ya que tienen la finalidad de planificar, controlar e impulsar el desarrollo del territorio rural y urbano. Mientras no haya planes reguladores que prohíban y controlen los asentamientos informales en zonas de riesgo; aunque se den bonos de vivienda, el problema prevalece porque llegan nuevas personas a vivir ahí. Esa es una de las razones por las que definir un plazo para el desarrollo de planes reguladores, capacitar a las personas sobre su aplicación, evaluarlos constantemente y readaptarlos, de manera consciente, para que sean verdaderos instrumentos de desarrollo y no camisas de fuerza incoherentes, es prioritario.

En segundo orden, reducir la brecha entre el poder ejecutivo y las municipalidades, aumentar la atención a las zonas rurales y activar las federaciones municipales ayudaría en el reconocimiento de necesidades y el levantamiento de información actualizada para que, con base en las fichas de información social, se atienda oportunamente a las personas.

Es de conocimiento popular que hay un divorcio entre la población y las municipalidades. Una parte de la población tiene la noción de que las municipalidades son vagas y corruptas. Hay un problema de credibilidad de por medio. Sin embargo, es un compromiso hacer que lo público funcione. Esto requiere pensar en términos de municipio, más que de municipalidad; en donde el municipio vendría a ser la comunidad sumada al gobierno local y lograr la coordinación real entre instituciones. Esa transinstitucionalidad quiere decir, mejor comunicación. Es lo que nos conduciría a un plan país para regular el crecimiento urbano, procurando vivienda de huella pequeña y alta densidad; además de, por ejemplo, aminorar las trabas que se dan cuando no se permite el traslado de personas a un proyecto habitacional por no pertenecer a un determinado cantón o aumentar nuestra eficiencia en el ciclo de reciclaje en el que la mayoría de las municipalidades solo se enfoca en tratar y disponer, cuando necesitamos ser más incidentes en la campaña para evitar, reducir, reutilizar y valorizar. Hoy, por fin vemos con urgencia la carbono neutralidad, la necesidad de atacar nuestra principal fuente de emisiones contaminantes (que es el sector transporte) y comprender que la ciudad es un sistema complejo en el que mejor infraestructura no significa hacer más calles.

Nuestra competitividad y economía se vuelven más vulnerables, pues el transporte, la accesibilidad de los espacios, los usos compartimentados y el desuso de nuevas tecnologías nos afectan directamente y nos hacen menos eficientes. La tecnología 
BIM (Building Information Modeling) apenas comienza a ingresar en nuestro país y estamos en un periodo de transición marcado por el uso extendido de softwares obsoletos. Esta tecnología permite estandarizar métodos; saber anticipadamente quiénes van a participar en un proyecto; acceder a modelos colaborativos de contratación; llegar a consensos más rápidamente para fijar metas en común; mayor flexibilidad a la hora de atender imprevistos, porque los cambios se pueden ejecutar desde el detalle y reflejarse en lo global, o cambiarse lo global y que los detalles de adapten; permite una mayor transparencia en la toma de decisiones y la ejecución, porque los cambios que se generan quedan almacenados en un archivo central; facilita la generación de prototipos, revisiones a larga distancia, conciliación entre todas las ingenierías y mejor uso del 'big data'; todo lo lo que facilita obtener mayor precisión en los presupuestos y cronogramas; así como un mayor control sobre el proceso.

El resultado se vuelve tan accesible, que permite enfocarse en el proceso, para encarar áreas que muchas veces son relegadas, como la planificación, coordinación, generación de indicadores y socialización del proyecto. Pasamos de ser la sociedad industrializada, a ser la sociedad de la información y el conocimiento, por lo que la tecnología de ciudades inteligentes debe ser un medio y no un fin. No es suficiente con tener videovigilancia, postes y agujas inteligentes; debe ser una respuesta inteligente al cambio climático y a la atención de problemas sociales.

Por esto el acceso a una buena educación en todas las disciplinas asociadas al diseño, construcción, dinámica y modo de operar de una ciudad es decisivo. Es urgente reducir la disociación entre la academia y la práctica. Las universidades deben tener una mayor injerencia sobre estos temas, fortalecer la investigación y producción científica, crear proyectos con incidencia social tangible, hacer escuchar su voz en temas de actualidad, promover experiencias propias de la vida profesional desde la academia y formar profesionales capaces de visualizar las crisis del futuro, y formular y autogestionar proyectos. Crear mejores lazos interuniversitarios, que integren expertos, líderes comunales, personas de la sociedad civil que se encuentran comprometidas e interesadas, investigadores independientes o estudiantes de primer ingreso, en temas de política pública, local o territorial, con acciones educativas dirigidas al fortalecimiento de capacidades individuales.

Capacitarlos, no para prestar servicios de manera operativa, sino para ser estrategas y activistas del desarrollo local. Es cierto que, en algunos momentos de la vida universitaria, la ciudad parece un laboratorio, lleno de posibilidades infinitas; pero hay que hacer un esfuerzo por aterrizar y madurar para dejar de ver la ciudad desde las opiniones academicistas que ven las problemáticas por encima del hombro, como si supieran resolverlas, pero con mucha modestia para asumir algún liderazgo. 
La ciudad no es un juego y no se puede estudiar desde las clases magistrales y los estudios de caso solamente. Obligarse a salir, comprobar las calidades de los espacios, hablar con la gente, proponer no para ganar un concurso o figurar en un encabezado, tener curiosidad y empatía son parte importante de los aprendizajes. Esas convicciones que surgen desde las primeras experiencias con la ciudad son las que toman fuerza para continuar investigando y leyendo, y son las que dan origen a profesionales sensibles y comprometidos con el binomio casa-ciudad.

Hay que dar vida a cursos de economía, derecho, geografía, sociología y antropología con enfoque urbano dentro de los planes de estudio de las escuelas de arquitectura. Procurar que el profesorado esté involucrado fuertemente en investigación y movimientos sociales ayuda a crear insumos en donde es más fácil para los estudiantes dilucidar la dimensión práctica de lo teórico, empaparse de información de interés (por estar vinculada a las realidades del país) y sumarse a las iniciativas con mayor entusiasmo.

Un ejemplo de ello fue el XVI Taller Social Latinoamericano de Estudiantes de Arquitectura Costa Rica 2019, el cual es un evento académico organizado por la Coordinadora Latinoamericana de Estudiantes de Arquitectura (CLEA) y la organización local Estudiantes de Arquitectura en Movimiento (EAM) que tuvo lugar en esta ocasión en las comunidades de Jerusalem, Chorotega y Río Cañas Viejo en Santa Cruz, Guanacaste; donde se tuvo la oportunidad de salir de las aulas, socializar, hacer diseño en conjunto con variedad de personas, construir y proveer equipamientos urbanos que impacten positivamente el lugar. Sucede que “... los riegos actuales que afronta la población joven han permeado el tradicional adultismo de los liderazgos comunitarios ..." (Paniagua \& Salgado, 2012, p.32) y lo mismo debiera suceder en la realización de actividades académicas y profesionales, en donde jóvenes, ciudadanos, gobierno local, políticos y desarrolladores, deben estar involucrados, pues esto permite que la población se mantenga informada, haya un proceso de sensibilización especialmente para que las personas tengan mayor acceso al poder para hacer un cambio real y que haya cada vez mayor consenso sobre cuáles son las prioridades y errores que se han cometido en materia de hogar y ciudad.

\section{Referencias}

Agencia de Ecología Urbana de Barcelona. (2019) Carta para la planificación ecosistémica de ciudades y metrópolis http://www.cartaurbanismoecosistemico.com/CARTA\%20PARA\%20 LA\%20PLANIFICACI\%C3\%93N\%20ECOSIST\%C3\%89MICA\%20DE\%20LAS\%20 CIUDADES.pdf

Bachelard, G. (2000). La poética del espacio. Fondo de Cultura Económica. 
Boullée, E. (1972). Etienne-Louis Boullée: Ensayo sobre el arte Revista de Ideas Estéticas 119, $243-267$.

Defensoría de los Habitantes. (2012). Informe anual de labores 2011-2012. https://issuu.com/ defensoriadeloshabitantescr/docs/informeanual_2011-2012

Defensoría de los Habitantes. (2018). Informe anual de labores 2017-2018. http://www.asamblea. go.cr/glcp/Informes_defensoria/Informe\%20Anual\%20de\%20Labores\%20de\%20la\%20 Defensor\%C3\%ADa $\% 20 \mathrm{de} \% 201$ os\%20Habitantes $\% 20$ correspondiente $\% 20 \mathrm{al} \% 20$ per\%C3\%ADodo\%202017-2018.pdf

Ferreira D. (2014). Cuarentena (muestra de arte digital). https://artedaliaferreira.wordpress. com/2014/04/27/105/

Ferrufino, C. Grande, C. (2013). Tendencias del Ordenamiento Territorial en América Central y República Dominicana (2009-2012). San Salvador: Cooperación Alema-na para el Desarrollo (GIZ).

Foster, H. (2000) Contra el pluralismo. La Gaceta de Cuba, 5, 34-39. http://www.criterios.es/ pdf/fosterpluralismo.pdf

Geertz, C. (1973) La interpretación de las culturas. Editorial Gedisa.

Gobierno de Costa Rica. (2004). Decreto 31730-MIDEPLAN-MIVAH: Crea Programa de Regeneración y Repoblamiento de San José. Sistema Costarricense de Información Jurídica.

Gobierno de Costa Rica. (2019). Plan nacional de desarrollo y de inversión pública del Bicentenario 2019-2022 de Costa Rica. https://observatorioplanificacion.cepal.org/es/planes/plan-nacional-de-desarrollo-y-de-inversion-publica-del-bicentenario-2019-2022-de-costa-rica

Jacobs, J. (2011). Muerte y vida de las grandes ciudades. Capitán Swing Libros.

Molina, X. (2004). Ser o no ser pobre. Campus Digital. http://www.campus.una.ac.cr/ediciones/2004/setiembre/2004setiembre_pag08.html

Heidegger, M. (1994). Conferencias y artículos (Barjau, E., trad.). Ediciones del Serbal.

Lévi-Strauss, C. (1988). Tristes trópicos. Editorial Paidós.

Núñez, M. (29 de mayo de 2018). Urge mayor planificación urbana que garantice derecho a la ciudad. Semanario Universidad. https://semanariouniversidad.com/pais/ urge-mayor-planificacion-urbana-que-garantice-derecho-a-la-ciudad/

ONU. (1966). Pacto Internacional de Derechos Económicos, Sociales y Culturales de la ONU. https://www.ohchr.org/SP/ProfessionalInterest/Pages/CESCR.aspx 
ONU Hábitat. (2014). Construcción de ciudades más equitativas. Políticas públicas para la inclusión en América Latina. Programa de la Naciones Unidas para los Asentamientos Humanos. http:// publicaciones.caf.com/media/39869/construccion_de_ciudades_mas_equitativas_web0804. pdf

Ortiz, M. (2012). Autoconciencia, ciencia y filosofía en la relación hombre-naturaleza. Revista Omnia, 18(1), 109-120.

Pallasmaa, J. (2006). Los ojos de la piel: La arquitectura y los sentidos. Editorial Gustavo Gili.

Paniagua, L. Salgado, I. (Compiladores). (2012). Barrios para la gente: Políticas locales sobre vivienda y hábitat con enfoque de género y gestión del riesgo en Centroamérica. Universidad de Costa Rica, Escuela de Arquitectura.

Programa Estado de la Nación. (2016). Estado de la nación en desarrollo humano sostenible, (22). https://estadonacion.or.cr/informes/

Programa Estado de la Nación. (2018). Estado de la nación en desarrollo humano sostenible, (24) https://estadonacion.or.cr/informes/

Ruiz-Tagle, J. (2016). La segregación y la integración en la sociología urbana: Revisión de enfoques y aproximaciones críticas para las políticas públicas. Revista INVI, 31(87), pp. 9-57. https://doi.org/10.4067/s0718-83582016000200001

Smith, A. (1996). La riqueza de las naciones. Alianza Editorial.

Vidal, F. (2009). Pan y rosas. Fundamentos de exclusión social y empoderamiento. Cáritas Española Editores, Fundación FOESSA.

Xirau, R. (1993). Palabra y silencio. Siglo Veintiuno Editores.

Zambrano, M. (2001). La ciudad, creación histórica. En Aurora: Papeles del "Seminario María Zambrano”, N³, Revistas Catalanas de Acceso Abierto, Universidad de Barcelona, pp. 140-141. 